Parasitology

cambridge.org/par

\section{Research Article}

Cite this article: Cringoli $\mathrm{G}$ et al. (2021). The Kubic FLOTAC microscope (KFM): a new compact digital microscope for helminth egg counts. Parasitology 148, 427-434. https:// doi.org/10.1017/S003118202000219X

Received: 18 July 2020

Revised: 26 October 2020

Accepted: 5 November 2020

First published online: 20 November 2020

\section{Key words:}

Digital microscope; fecal egg count; Kubic FLOTAC microscope; Mini-FLOTAC; TeleParasitology

\section{Author for correspondence:}

Maria Paola Maurelli,

E-mail: mariapaola.maurelli@unina.it

\title{
The Kubic FLOTAC microscope (KFM): a new compact digital microscope for helminth egg counts
}

\section{Giuseppe Cringoli ${ }^{1}$, Alessandra Amadesi ${ }^{1}$, Maria Paola Maurelli ${ }^{1}(\mathbb{D}$, Biase Celano을 Gabriele Piantadosi ${ }^{3}$, Antonio Bosco ${ }^{1}$, Lavinia Ciuca ${ }^{1}$, Mario Cesarelli ${ }^{3}$, Paolo Bifulco ${ }^{3}$, Antonio Montresor ${ }^{4}$ and Laura Rinaldi ${ }^{1}$}

${ }^{1}$ Department of Veterinary Medicine and Animal Production, University of Naples Federico II, CREMOPAR, WHO Collaborating Centre ITA-116, Naples, Italy; ${ }^{2}$ Officina Elettronica SPA S.r.l., Naples, Italy; ${ }^{3}$ Department of Electrical Engineering and Information Technology, University of Naples Federico II, Naples, Italy and ${ }^{4}$ Department of Control of Neglected Tropical Diseases, World Health Organization, Geneva, Switzerland

\begin{abstract}
The Kubic FLOTAC microscope (KFM) is a compact, low-cost, versatile and portable digital microscope designed to analyse fecal specimens prepared with Mini-FLOTAC or FLOTAC, in both field and laboratory settings. In this paper, we present the characteristics of the KFM along with its first validation for fecal egg count (FEC) of gastrointestinal nematodes (GINs) in cattle. For this latter purpose, a study was performed on 30 fecal samples from cattle experimentally infected by GINs to compare the performance of Mini-FLOTAC either using a traditional optical microscope (OM) or the KFM. The results of the comparison showed a substantial agreement (concordance correlation coefficient $=0.999$ ), with a very low discrepancy $(-0.425 \pm 7.370)$ between the two microscopes. Moreover, the KFM captured images comparable with the view provided by the traditional OM. Therefore, the combination of sensitive, accurate, precise and standardized FEC techniques, as the Mini-FLOTAC, with a reliable automated system, will permit the real-time observation and quantification of parasitic structures, thanks also to artificial intelligence software, that is under development. For these reasons, the KFM is a promising tool for an accurate and efficient FEC to improve parasite diagnosis and to assist new generations of operators in veterinary and public health.
\end{abstract}

\section{Introduction}

Currently, the most widely used methods for diagnosis of intestinal parasites in both field and laboratory settings are fecal egg count (FEC) techniques, based on the microscopic identification and count of parasitic structures (eggs, larvae, oocysts and cysts) in fecal specimens, e.g. McMaster, Kato-Katz, FLOTAC, FECPAK, Mini-FLOTAC (MAFF, 1986; Cringoli et al., 2010, 2017; Levecke et al., 2011, 2012; WHO, 2019). Also, the availability of a reliable, low-cost, easy-to-use and quantitative test to perform the fecal egg count reduction test (FECRT) is of pivotal importance to facilitate the monitoring of deworming programmes in endemic countries (Cools et al., 2019) and to determine anthelmintic efficacy/resistance in consideration of the growing concern of the emergence of anthelmintic resistance in humans (Vlaminck et al., 2019), livestock (Vercruysse et al., 2018; Kaplan, 2020) and pet animals (Jimenez Castro et al., 2019; Kitchen et al., 2019).

Among the above mentioned techniques, Mini-FLOTAC, in particular, is considered a good candidate for a standardized FEC/FECRT either in lab or in field setting (Nikolay et al., 2014; Dias de Castro et al., 2017; George et al., 2017; Paras et al., 2018; Cools et al., 2019; Rinaldi et al., 2019; Amadesi et al., 2020). However, the Mini-FLOTAC, as all the other FEC techniques, requires specialized personnel and is time-consuming, especially when a large number of specimens are examined like in case of large epidemiological surveys (Cringoli et al., 2017; Vercruysse et al., 2018; Sukas et al., 2019).

Recently, the use of new technologies is beginning to offer potential solutions to overcome gaps and limitations of FEC techniques (i.e. human errors and time for analysis). Recent studies have evaluated different smartphone-based technologies to magnify objects, to capture images or to perform an automated identification of endoparasites (i.e. protozoa and helminths), showing a good potential for wider application. Saeed and Jabbar (2018) reviewed the applications of various smartphone-based methods and devices developed from 1990 to 2017 for the diagnosis of different parasites of public health relevance (e.g. soil-transmitted helminths, Schistosoma spp., protozoa, etc.). Moreover, several studies, reported in Table 1, focused on the development of semi-automated and automated systems for assessing FEC in the veterinary field. However, these systems have shown difficulties in commercialization, mainly due to their low sensitivity and accuracy, high costs and/or the limited data on validations in the lab and/or in the field. For these reasons, we consider that there is still the need for a reliable automated system that improves the efficiency of parasitological diagnosis in veterinary medicine and public health at an affordable cost. 
Table 1. Semi-automated and automated systems for parasite detection in humans and animals (principle, the hosts from which fecal samples were collected, the parasites detected, the advantages, limits and references)

\begin{tabular}{|c|c|c|c|c|c|c|}
\hline Method & Principle & Hosts & Parasites & Advantages & Limitations & References \\
\hline FECPAK $^{\mathrm{G} 2}$ & $\begin{array}{l}\text { High-throughput technological } \\
\text { system for on-field sample } \\
\text { processing }\end{array}$ & $\begin{array}{l}\text { Ruminants; } \\
\text { humans }\end{array}$ & $\begin{array}{l}\text { GINs; } \\
\text { soil-transmitted } \\
\text { helminths (STH) }\end{array}$ & $\begin{array}{l}\text { Automated detection and } \\
\text { count; remote parasite } \\
\text { detection and data online } \\
\text { management }\end{array}$ & Low sensitivity and accuracy & $\begin{array}{l}\text { Mirams, (2016); Rashid et al. (2018); } \\
\text { Moser et al. (2018); Vlaminck et al. } \\
\text { (2018); Cools et al. (2019); Vlaminck } \\
\text { et al. (2019) }\end{array}$ \\
\hline Parasight system & $\begin{array}{l}\text { Based on a fluorescent egg } \\
\text { staining and a smartphone to } \\
\text { capture images }\end{array}$ & Horses & $\begin{array}{l}\text { Strongyles and } \\
\text { Parascaris equorum }\end{array}$ & $\begin{array}{l}2.5 \text { min test time, less } \\
\text { variables and more } \\
\text { accurate than McMaster } \\
\text { technique }\end{array}$ & Validated only on horses & $\begin{array}{l}\text { Slusarewicz et al. (2016); Scare et al. } \\
\text { (2017); Cain et al. (2020) }\end{array}$ \\
\hline $\begin{array}{l}\text { Lab-on-disk } \\
\text { platform }\end{array}$ & $\begin{array}{l}\text { Based on a combined } \\
\text { gravitational and centrifugal } \\
\text { flotation and the use of a } \\
\text { converging collection chamber } \\
\text { to create a monolayer of eggs }\end{array}$ & Humans; pigs & $\begin{array}{l}\text { STH, Schistosoma } \\
\text { mansoni; Ascaris suum }\end{array}$ & $\begin{array}{l}\text { High-quality of images, } \\
\text { permitting a good } \\
\text { identification and count }\end{array}$ & $\begin{array}{l}\text { High cost; potentially limited use in } \\
\text { field, due to: (i) the need for a } \\
\text { minicentrifuge; (ii) the need for } \\
\text { electricity and (iii) relatively large } \\
\text { size/difficult to carry over distance }\end{array}$ & Sukas et al. (2019) \\
\hline $\begin{array}{l}\text { Automated } \\
\text { robotic system }\end{array}$ & $\begin{array}{l}\text { Based on an automated } X-Y \\
\text { stage; the autofocusing and } \\
\text { scanning function are based on } \\
\text { LabVIEW GUI }\end{array}$ & $\begin{array}{l}\text { Monkey; dogs; } \\
\text { sheep; cattle }\end{array}$ & $\begin{array}{l}\text { Trichuris spp., Toxocara } \\
\text { spp., strongyle, } \\
\text { Isospora spp., Eimeria } \\
\text { spp. }\end{array}$ & $\begin{array}{l}\text { Inexpensive ( US\$350), } \\
\text { compact, possibility to } \\
\text { use fluorescence }\end{array}$ & $\begin{array}{l}\text { The system can be used only with } \\
\text { McMaster chamber; not validated }\end{array}$ & Lu et al. (2018); Li et al. (2019) \\
\hline $\begin{array}{l}\text { Automated } \\
\text { diagnosis of } \\
\text { intestinal } \\
\text { parasites (DAPI) }\end{array}$ & $\begin{array}{l}\text { Based on a motorized system to } \\
\text { read slides, using a digital } \\
\text { camera and machine learning } \\
\text { software }\end{array}$ & Dogs & $\begin{array}{l}\text { Ancylostoma spp., } \\
\text { Toxocara spp., Trichuris } \\
\text { spp., and Giardia spp. }\end{array}$ & $\begin{array}{l}\text { Automated detection of } \\
\text { eggs through machine } \\
\text { learning software }\end{array}$ & $\begin{array}{l}\text { High cost; not portable; not } \\
\text { validated }\end{array}$ & Inácio et al. (2020) \\
\hline $\begin{array}{l}\text { Telenostic } \\
\text { system }\end{array}$ & $\begin{array}{l}\text { Automated digital microscope } \\
\text { with a } 10 \times \text { lens using machine } \\
\text { learning software }\end{array}$ & Cattle & GINs & $\begin{array}{l}\text { High level of agreement } \\
\text { between the prototype } \\
\text { and manual systems of } \\
\text { FEC (i.e. McMaster and } \\
\text { Mini-FLOTAC) }\end{array}$ & $\begin{array}{l}\text { Validated only on cattle; it requires } \\
\text { long time to acquire and analyse } \\
\text { the images (approximately } 42 \mathrm{~min} \text { ) }\end{array}$ & Elghryani et al. (2020) \\
\hline $\begin{array}{l}\text { VETSCAN } \\
\text { IMAGYST }\end{array}$ & $\begin{array}{l}\text { Composed of a digital slide } \\
\text { scanner and machine learning } \\
\text { software }\end{array}$ & Dogs and cats & $\begin{array}{l}\text { Ancylostomidae, } \\
\text { Toxocara spp., Trichuris } \\
\text { spp., Taeniidae }\end{array}$ & $\begin{array}{l}\text { The system allows } \\
\text { identification and count } \\
\text { of eggs within } 15 \mathrm{~min}\end{array}$ & $\begin{array}{l}\text { High cost; not portable; validated } \\
\text { only on dogs and cats }\end{array}$ & Nagamori et al. (2020) \\
\hline
\end{tabular}



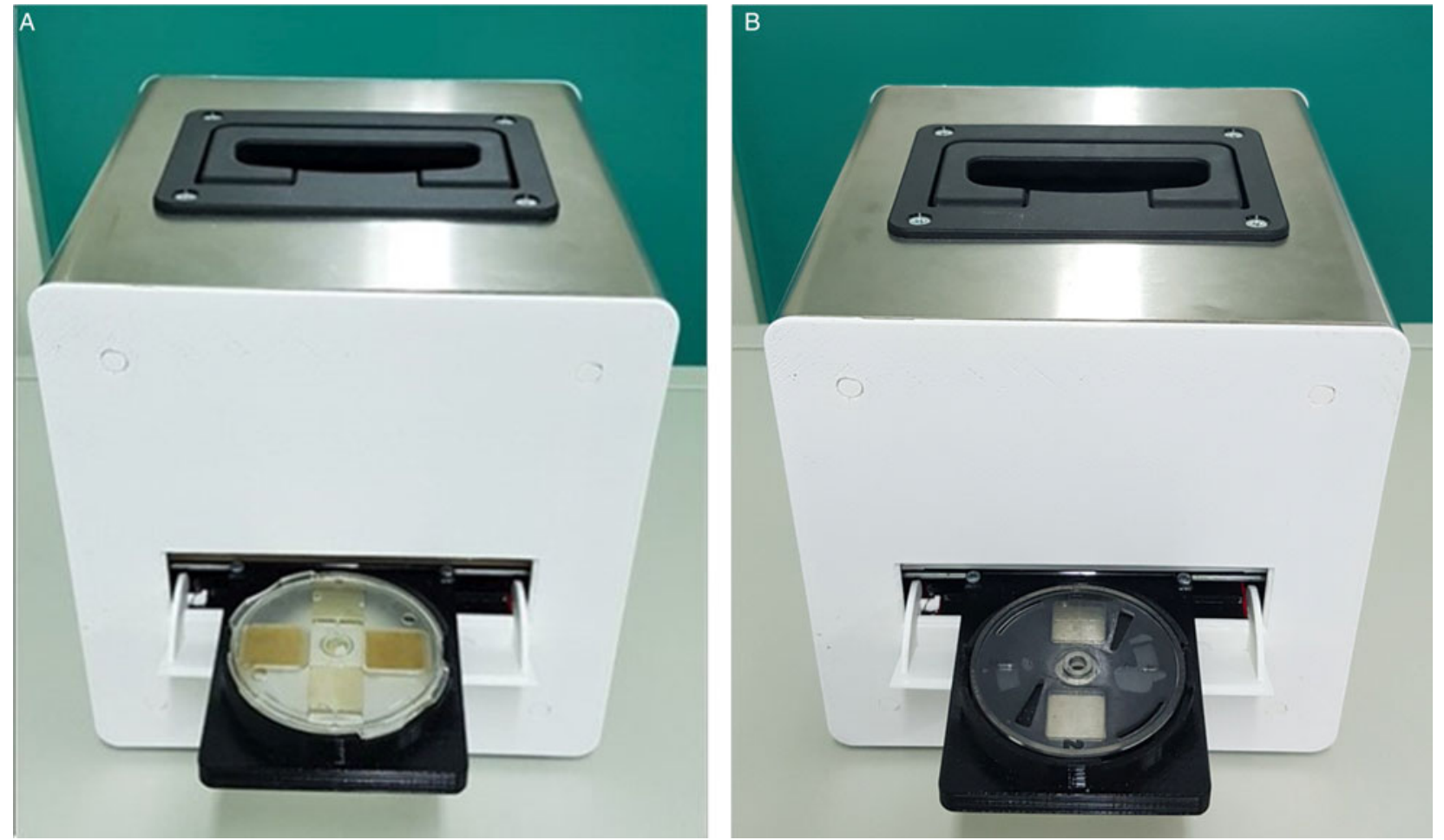

Fig. 1. KFM used with the Mini-FLOTAC (A) and FLOTAC devices (B).

In this paper, we present the characteristics of the Kubic FLOTAC microscope (KFM), a new compact, cubic in shape $(20 \times 20 \times 20 \mathrm{~cm})$, low-cost $(\sim 600$ euros $)$, versatile and portable digital microscope capable of scanning fecal specimens prepared with Mini-FLOTAC or FLOTAC (Mini-FLOTAC/FLOTAC) (Fig. 1A and B). The KFM can be used also directly in field, because it does not need any additional special requirement (e.g. centrifuge or any electricity source), being provided of a lithium battery with an autonomy up to $20 \mathrm{~h}$. Moreover, we report the findings of the first validation of the KFM to perform FEC of gastrointestinal nematodes (GINs) in cattle using the Mini-FLOTAC technique and compare the results obtained by KFM with those obtained by a traditional optical microscope (OM).

\section{Materials and methods}

\section{The Kubic FLOTAC microscope (KFM) description}

The KFM is composed of an electromechanical part that allows a three-dimensional (3D) scan of the Mini-FLOTAC/FLOTAC (reading discs) and software that allows remote interactions and digital image processing supported by artificial intelligence (AI) for the recognition of helminth eggs and other parasitic structures. FreeCAD (open source, LGPL license) and Design Spark Mechanical (RS-components, Corby, UK) software were used to perform the 3D mechanical of the KFM (Fig. 2A and B). Once opportunely prepared, you can insert the Mini-FLOTAC or FLOTAC devices into a specific slide-out tray of the KFM (similarly to inserting a DVD into a player). Then, the tray is withdrawn inside and specific 3D landmarks corresponding to the corners of the two flotation chambers of the Mini-FLOTAC/ FLOTAC are automatically located. The KFM scanning device is equivalent to a $X Y Z$ motorized stage for microscopy.

The $3 \mathrm{D}$ positioning system of the motorized stage is based on a simple, non-standard Cartesian motor system solution and is provided with open-loop stepper motors coupled with precision translation stages to achieve accurate $3 \mathrm{D}$ motion control (Fig. 2C and D). A standard, low-cost stepper motor driver based on Arduino nano-board 105 (Arduino AG, Ivrea, Italy) and a free Grbl firmware were adopted to remote control of the KFM.

The KFM optical part is mainly composed of an LED light source with a condenser, which provides brightness adjustment, and a digital camera, which permits adjustable magnification at $100 \times, 200 \times, 300 \times$, with a maximum resolution of 8 MPixel $(3264 \times 2448$ pixel $)$ and the size of image of $1024 \times 768(0.8 \mathrm{Mp})$ (Fig. 3). A Raspberry PI (Raspberry Pi Foundation, Caldecote, UK) permits the remote control of the optical part. The motorized stage can automatically move stepwise to entirely scan the two flotation chambers of the Mini-FLOTAC/FLOTAC. For each step, the KFM camera captures a picture (or a Z-stack). Eventually, you can photograph the whole surface of the flotation chambers (each 18 $\mathrm{mm}$ by $18 \mathrm{~mm}$ wide) and the software stitches the multiple photos to obtain only one picture to perform the visual recognizing and the count of parasitic structures.

The KFM system has various options for external connectivity: (i) two USB ports to easily transfer the captured images; (ii) an Ethernet cable connector, a Bluetooth and a Wi-Fi wireless connection, which permit all users to easily transfer, share and backup the captured images to other devices. In addition, you can fully control the KFM using software by an external device, i.e. a smartphone, a tablet or a PC. A web interface permits the remote control of the KFM (Fig. 4); the internal software works on Linux operating system. Such an interface can be activated using any web browser. The remote interface supports Android 4.1, iOS 8.0, Windows $7 / 8 / 10$ and MacOS X 10.8. We developed a specific app that allows the remote control of the KFM directly from mobile phones.

The software has two modalities: 'Administrator', passwordprotected, for the management of settings and mechanical movements and 'Viewer' to allow remote viewing. The images captured by the KFM can be stored in an Internet cloud and/or transmitted to a diagnostic hub for telediagnosis or parasitological consultation. 
A
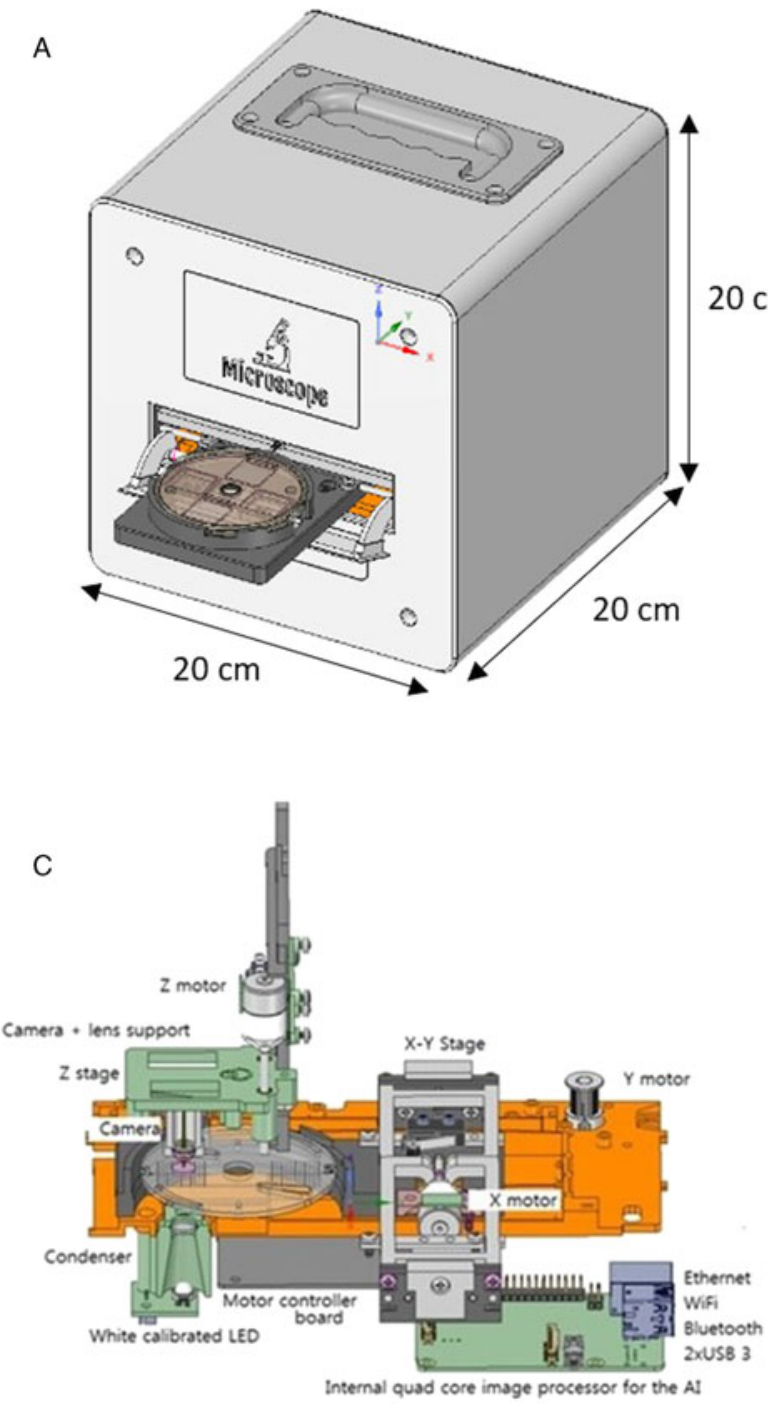
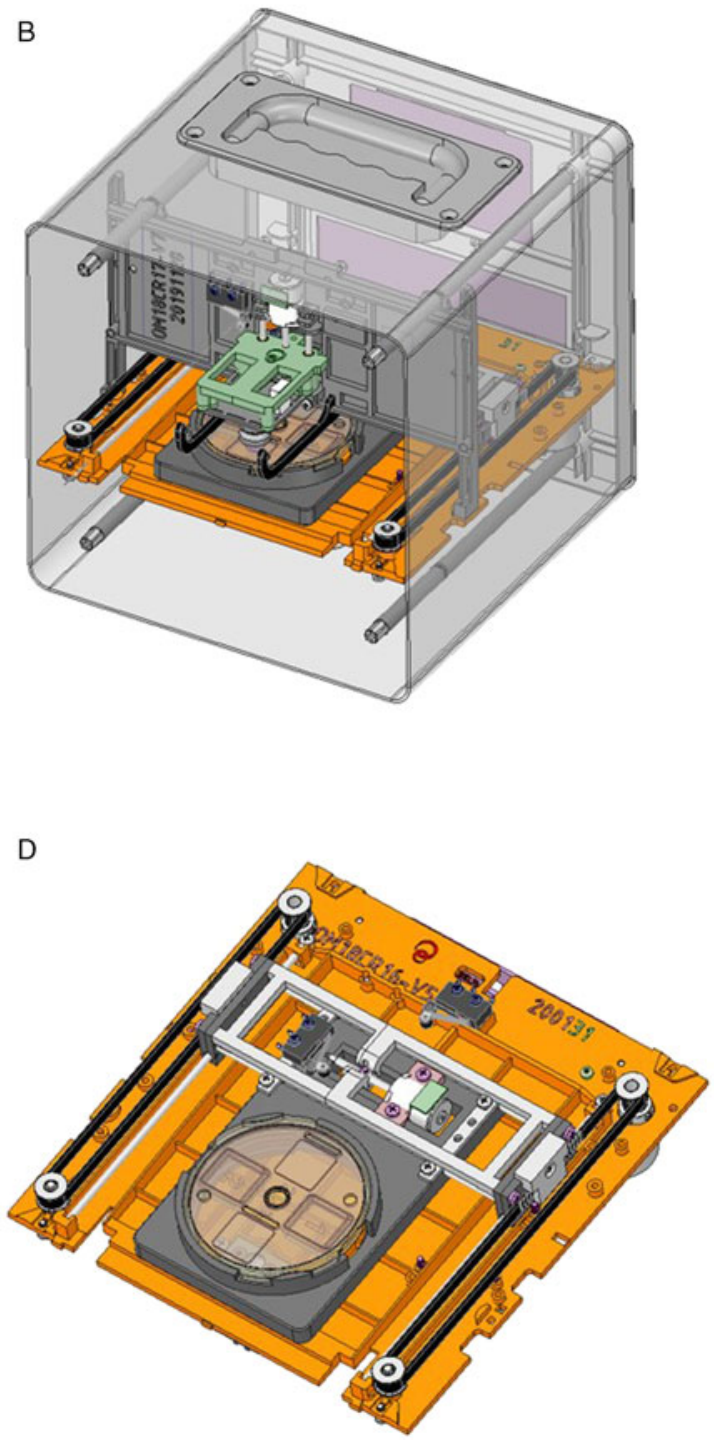

Fig. 2. (A) FreeCAD and Design Spark Mechanical of the KFM (external view); (B) FreeCAD and Design Spark Mechanical of the KFM (internal view); (C) Schematic diagram showing mechanical, electronic and optical systems of the KFM and (D) a particular of the handling motor based on the no-standard Cartesian system.

A

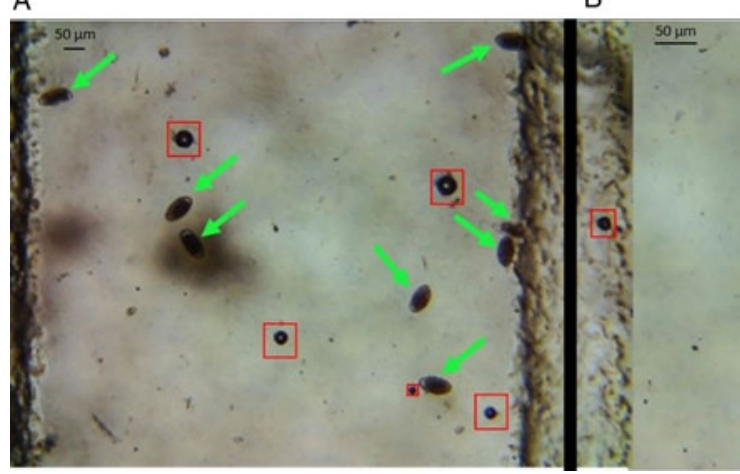

\section{B}

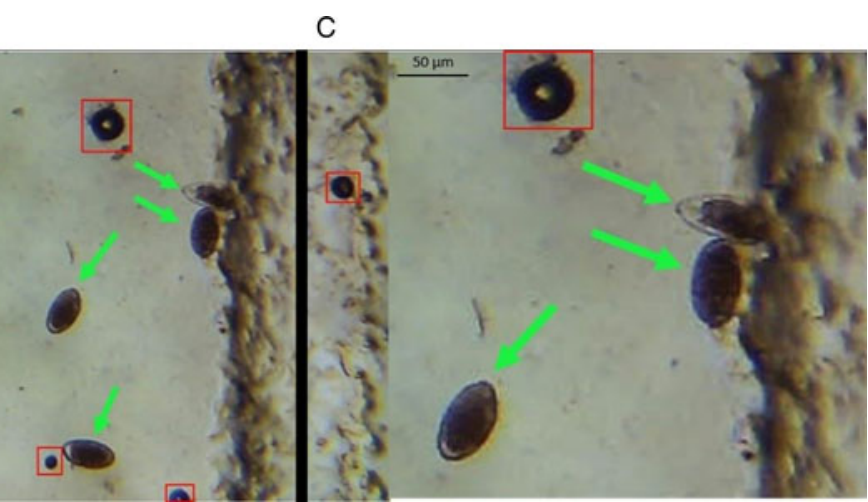

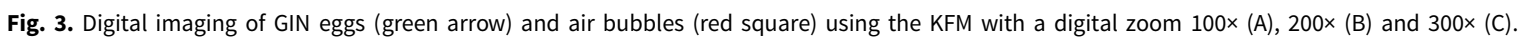

At the moment, for these characteristics, you can use the KFM as a digital microscope, instead of an OM, remotely controlled to perform the visual identification and counting of parasitic structures, as validated in this paper. Moreover, further developments are ongoing to update a fully automated version of KFM, as reported in the 'Discussion' section.

\section{Study sampling and laboratory activities}

From September to December 2019, 30 fecal samples were collected from Belgian Blue and Holstein cattle (6 months old) experimentally infected with 50000 third stage larvae (L3) of Cooperia oncophora ( $n=15$ calves) or Ostertagia ostertagi ( $n=15$ calves) stabled at the experimental farm of the Faculty of 


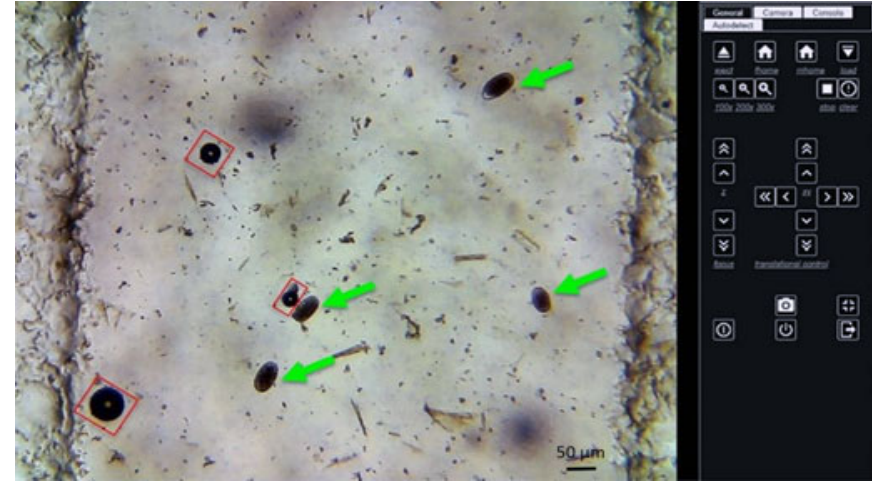

Fig. 4. Image of a part of a Mini-FLOTAC chamber, captured by technological devices (smartphone, tablet or a PC) connected with the microscope that shows GIN eggs (green arrows) and air bubbles (red squares).

Veterinary Medicine, Ghent University (Belgium). Then, we transferred the collected samples to the Department of Virology, Parasitology and Immunology of Ghent University. In the lab, an operator analysed six sub-samples for each fecal sample, filling six Fill-FLOTACs with $2 \mathrm{~g}$ of feces and homogenizing them with $38 \mathrm{~mL}$ (dilution ratio 1:20) of a saturated sodium chloride flotation solution (specific gravity $=1200$ ). Then, six Mini-FLOTAC devices were filled (one per each subsample), following the SOPs described in Cringoli et al. (2017). To ensure the quality of parasitological examination, one operator read the Mini-FLOTACs with an OM (Leica Microsystems, Wetzlar, Germany), then a second operator randomized the Mini-FLOTACs, before the reading with the KFM to obtain blinded results. Finally, the total time was evaluated to perform the Mini-FLOTAC technique either with the reading under the KFM or under a traditional OM.

\section{Statistical analysis}

A Mann-Whitney test was used to compare the readings by both microscopes. Moreover, we calculated the Lin's concordance correlation coefficient (CCC) and the corresponding 95\% confidence interval (CI) to quantify the agreement between the analysis using the OM and the KFM. The agreement was classified as poor,
Table 2. Number of counted eggs (sum and mean) for the analysis performed by the Mini-FLOTAC using a traditional OM and the KFM at low $(<10)$, medium $(10-25)$, high (>25) egg count levels and total counts

\begin{tabular}{lccccc}
\hline & \multicolumn{2}{c}{ OM } & & \multicolumn{2}{c}{ KFM } \\
\cline { 2 - 3 } \cline { 5 - 6 } Egg level & Sum & Mean & & Sum & Mean \\
\hline Low & 296 & 4.93 & 291 & 4.85 \\
\hline Medium & 834 & 13.90 & 827 & 13.78 \\
\hline High & 1761 & 29.35 & 1771 & 29.52 \\
\hline Total counts & 2891 & 16.06 & 2889 & 16.05 \\
\hline
\end{tabular}

moderate, substantial or almost perfect for CCC values $<0.9$, $0.90-0.95,0.95-0.99$ or $>0.99$, respectively (McBride, 2005). Finally, the level of agreement was analysed using the BlandAltman plot. All the statistical analyses were performed using GraphPad Prism v.8 (Graph Pad Software, San Diego, CA, USA) and SPSS Statistics v.23 (IBM, Armonk, NY, USA). All tests were considered statistically significant at $P<0.05$.

\section{Results}

In total, 180 counts were performed using the OM and 180 counts using the KFM. A range of GIN eggs from 1 to 62 was found for each sample analysed, as depicted in Fig. 5. Based on the counted eggs, each sample was assigned to one of the three egg count levels: low $(<10)$, medium $(10-25)$ and high $(>25)$. Table 2 shows the sum and mean egg counts detected by the OM and the KFM at the different count levels. The correlation and the agreement between counted eggs by both microscopes for each level, and total counts are reported in Figs 6 and 7.

The results analysed by the Mann-Whitney test showed that there was not a statistically significant difference $(P>0.05)$ between medians of counted eggs obtained with the two microscopes, for each egg count level. The CCC between the reading with OM and KFM was substantial for low $(\mathrm{CCC}=0.984 ; 95 \% \mathrm{CI}=0.973-$ $0.990)$, medium $(\mathrm{CCC}=0.981 ; 95 \% \mathrm{CI}=0.968-0.988)$ and high (CCC $=0.998 ; 95 \% \mathrm{CI}=0.996-0.999)$ egg count levels; similar findings were found when considering total egg counts $(\mathrm{CCC}=0.999$;

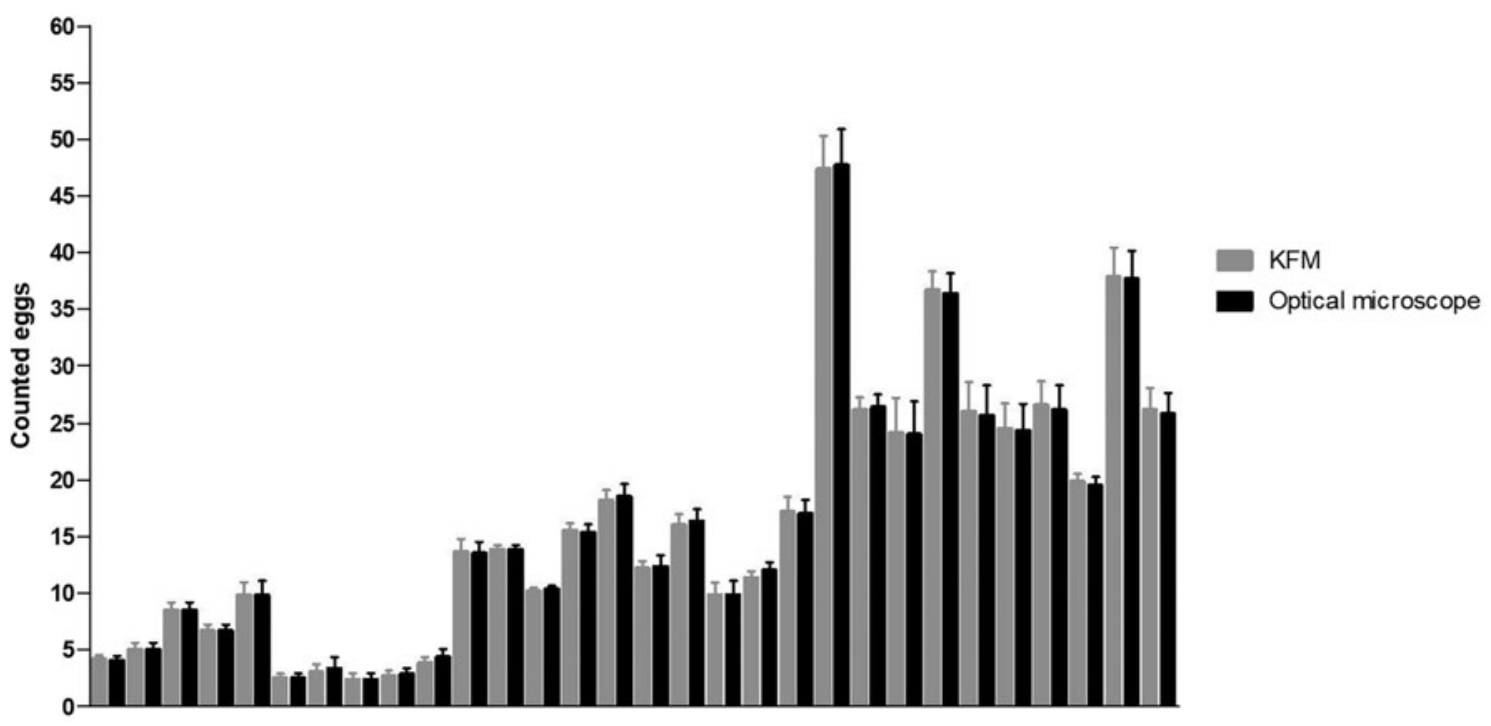

Sample No.

Fig. 5. Comparison of the mean of counted eggs between the readings by the OM and the KFM for each sample. 

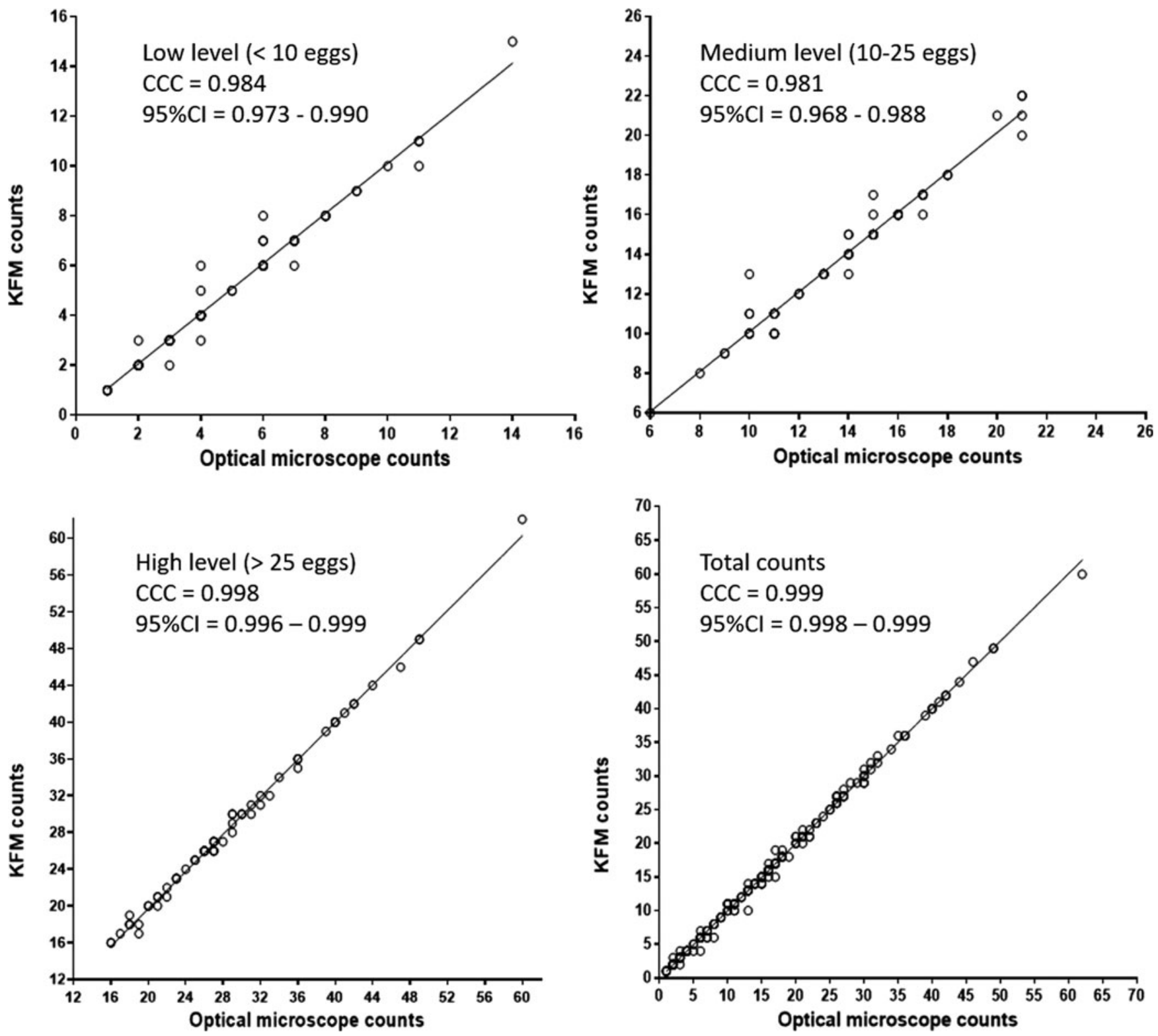

Fig. 6. Correlation between the number of counted eggs based on the examination of Mini-FLOTAC using the OM and KFM for each level of egg counts and total counts.

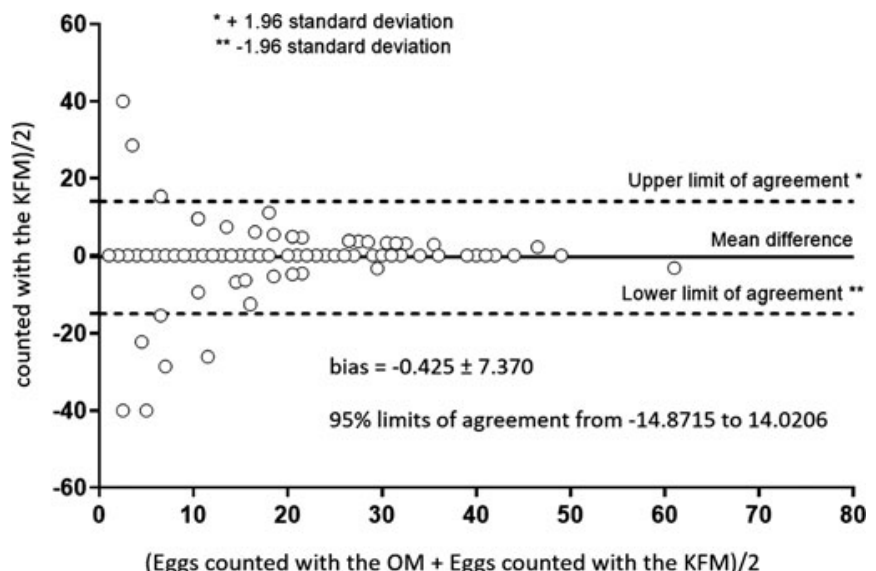

Fig. 7. Bland-Altman plot of number of counted GIN eggs based on the examination of Mini-FLOTAC using OM and KFM.

95\% CI $=0.998-0.999$ ) (Fig. 6). Furthermore, the Bland-Altman plot (Fig. 7) demonstrated an excellent agreement between the two reading approaches (bias $=-0.425 \pm 7.370$, with $95 \%$ limits
Table 3. Time of analysis to perform the Mini-FLOTAC technique with the traditional OM and the KFM for each step of the protocol used

\begin{tabular}{lll}
\hline Step & \multicolumn{1}{c}{ OM } & \multicolumn{1}{c}{ KFM } \\
\hline $\begin{array}{l}\text { Preparation of the sample using } \\
\text { Fill-FLOTAC and Mini-FLOTAC }\end{array}$ & $11 \mathrm{~min}$ & $11 \mathrm{~min}$ \\
\hline Reading of the Mini-FLOTAC & $1-5 \mathrm{~min}$ & $3-8 \mathrm{~min}$ \\
\hline Analysis of results & $5 \mathrm{~s}$ & $5 \mathrm{~s}$ \\
\hline Total & $\begin{array}{l}12-16 \mathrm{~min} \\
\text { and } 5 \mathrm{~s}\end{array}$ & $\begin{array}{l}14-19 \mathrm{~min} \\
\text { and } 5 \mathrm{~s}\end{array}$ \\
\hline
\end{tabular}

of agreement from -14.872 to 14.021). Finally, the time required to perform the Mini-FLOTAC technique with the KFM and the traditional $\mathrm{OM}$ is reported in Table 3.

\section{Discussion}

The KFM presented for the first time in this paper has proven a promising system for an accurate assessment of GIN egg counts in 
cattle. The results showed that there were not statistically significant differences between medians of counted eggs obtained with $\mathrm{OM}$ and KFM. Moreover, a substantial agreement $(\mathrm{CCC}=$ $0.999)$ and a low $(-0.425 \pm 7.370)$ discrepancy were found between the two microscopes. These findings were confirmed also by the Bland-Altman plot that was very useful to compare the egg counts obtained with the two microscopes. The BlandAltman plot showed a very low bias $(-0.425)$ and the absence of a systematic error, in fact points of the graph corresponding to the differences between the readings with the two systems are all around the line zero, showing a dispersion of the points only for the low egg count level ( $<10$ eggs), without outliers.

The time taken to scan and count the GIN eggs in the Mini-FLOTAC chambers under the KFM was $\sim 3-8$ min compared to $\sim 1-5$ min taken to read the Mini-FLOTAC under the traditional $\mathrm{OM}$ by the same skilled operator. However, the KFM system used in this comparison study was only a prototype, but we are developing an App that will allow us to improve the speed of scanning of the Mini-FLOTAC apparatus, thus reducing the time for analysis.

There are many advantages of the KFM compared to the OM, e.g.: (i) it can be used without requiring electricity in both laboratory and field settings; (ii) it is cheap ( €600) and (iii) it is able to transfer via internet the captured pictures to other laboratories or can be used by remote from another country. Therefore, it could be very useful to create a network of laboratories or to support operators directly in the field as expected by Tele-Medicine and Tele-Parasitology (Di Cerbo et al., 2015; Scheild et al., 2007; Zaffarano et al., 2018).

Moreover, this system is very easy to be performed by any operator without a specific training (it will be possible to use the KFM just following the manufacturer's instructions).

One of the future improvements of the KFM, actually under development, is the tuning of a predictive model, for the automated identification and counting of helminth eggs, based on AI (machine learning) using a single deep neural network, named Single Shot Multibox Detector (SSD) (Liu et al., 2016). For this aim, the use of high-quality images, as well as those captured by the KFM in our study, is fundamental. To date, to perform the first ground-truth phase of the training software a dataset with 11136 images of GIN eggs (confirmed by experts) from large and small ruminant feces was used. The acquired images are first elaborated to separate the parasitic structures from the background, which can be either impurities or pseudoparasites, through the use of ImageJ (National Institute of Health) with the main goal of being able to characterize the parasite species and to automatically count eggs (Grishagin, 2015).

In future, this software will be available also for other parasitic structures of veterinary and public health importance.

Therefore, KFM permits the combination of a sensitive, accurate, precise and standardized FEC techniques, as the Mini-FLOTAC/FLOTAC (Cringoli et al., 2010, 2017), with a reliable system to capture and analyse pictures. Moreover, thanks to the development of AI software for automated identification and counts, this system will allow a reduction in human errors and time of reading, increasing its diagnostic efficiency.

\section{Conclusions}

In conclusion, the KFM is a promising system that may, upon successful validation studies performed in different settings and laboratories of medical and veterinary parasitology, allow progression in overcoming the numerous limitations of traditional egg counting techniques.

The development of the AI predictive model will be very useful for an easy-to-use, low cost and precise automated system for identification and counting of parasitic structures allowing a rapid assessment of FEC/FECR to assist a new generation of operators (i.e. technicians, physicians, veterinarians and farmers) in veterinary and human parasitology and diagnostics. In principle, the KFM could also be adapted to read other fecal preparation slides such as the Kato-Katz or McMaster.

\section{Data}

All data generated or analysed during this study are included in this published paper. The datasets used and/or analysed during the current study are available from the corresponding author upon reasonable request.

Acknowledgements. The authors acknowledge M.E. Morgoglione, M. Santaniello, P. Pepe, D. Ianniello, S. Pennacchio and V. Musella for their participation in the development of the Kubic FLOTAC microscope. Moreover, they would like to express sincere appreciation to Prof. E. Claerebout, Prof. B. Levecke, N. De Wilde, S. Casaert and all the Department of Virology, Parasitology and Immunology of the Faculty of Veterinary Medicine, Ghent University, Belgium, for their collaboration.

Author contribution. Invented the KFM: GC; all the authors participated in the KFM development. Conceived, designed and coordinated the validation study of the KFM to perform FEC of GINs in cattle: GC, LR and MPM. Performed sampling and laboratory analyses: AA. Performed the first groundtruth phase of training software: GP and AA. All authors contributed to data analysis and interpretation, and preparation of the manuscript. All authors read and approved the final manuscript.

Financial support. This research did not receive any specific grant from funding agencies in the public, commercial or not-for-profit sectors.

Conflict of interest. The Mini-FLOTAC technique was developed and is patented by GC, but the patent has been handed over to the University of Naples Federico II. The fact that GC is the current patent holder of the Mini-FLOTAC and Fill-FLOTAC had no role in the preparation and submission of the protocols reported or the design and implementation of ongoing and future studies. To obtain Mini-FLOTAC or Fill-FLOTAC devices, a contribution is required that is used only to cover costs of production and packaging, and to contribute to the ongoing FLOTAC research. The remaining authors declare that they have no competing interests.

\section{References}

Amadesi A, Bosco A, Rinaldi L, Cringoli G, Claerebout E and Maurelli MP (2020) Cattle gastrointestinal nematode egg-spiked faecal samples: high recovery rates using the Mini-FLOTAC technique. Parasites \& Vectors 6, 230

Cain JL, Slusarewicz P, Rutledge MH, McVey MR, Wielgus KM, Zynda KM, Wehling LM, Scare JA, Steuer AE and Nielsen MK (2020) Diagnostic performance of McMaster, Wisconsin, and automated egg counting techniques for enumeration of equine strongyle eggs in fecal samples. Veterinary Parasitology 284, 109-117.

Cools P, Vlaminck J, Albonico M, Ame S, Ayana M, José Antonio BP, Cringoli G, Dana D, Keiser J, Maurelli MP, Maya C, Matoso LF, Montresor A, Mekonnen Z, Mirams G, Corrêa-Oliveira R, Pinto SA, Rinaldi L, Sayasone S, Thomas E, Verweij JJ, Vercruysse J and Levecke B (2019) Diagnostic performance of a single and duplicate Kato-Katz, Mini-FLOTAC, FECPAKG2 and qPCR for the detection and quantification of soil-transmitted helminths in three endemic countries. PLoS Neglected Tropical Diseases 13, e0007446.

Cringoli G, Rinaldi L, Maurelli MP and Utzinger J (2010) FLOTAC: new multivalent techniques for qualitative and quantitative copromicroscopic diagnosis of parasites in animals and humans. Nature Protocols 5, 503-515.

Cringoli G, Maurelli MP, Levecke B, Bosco A, Vercruysse J, Utzinger J and Rinaldi L (2017) The Mini-FLOTAC technique for the diagnosis of helminth and protozoan infections in humans and animals. Nature Protocols 12, 1723-1732.

Dias de Castro LL, Abrahao CLH, Buzatti A, Molento MB, Bastianetto E, Rodrigues DS, Lopes LB, Silva XM, Freitas MG, Conde MH and de 
Almeida Borgese F (2017) Comparison of McMaster and mini-FLOTAC fecal egg counting techniques in cattle and horses. Veterinary Parasitology: Regional Studies and Reports 10, 132-135.

Di Cerbo A, Morales-Medina JC, Palmieri B and Ianniti T (2015) Narrative review of Tele-Medicine consultation in medical practice. Patient Preference and Adherence 9, 65-75.

Elghryani N, Crispell J, Ebrahimi R, Krivoruchko M, Lobaskin V, McOwan T, O'Connor W, Power E, Voisin B, Scholz D and de Waal T (2020) Preliminary evaluation of a novel, fully automated, Telenostic device for rapid field-diagnosis of cattle parasites. Parasitology 24, 1-5.

George MM, Paras KL, Howell SB and Kaplan RM (2017) Utilization of composite fecal samples for detection of anthelmintic resistance in gastrointestinal nematodes of cattle. Veterinary Parasitology 240, 24-29.

Grishagin IV (2015) Automatic cell counting with ImageJ. Analytical Biochemistry 473, 63-65.

Inácio SV, Gomes JF, Falcão AX, Celso Suzuki TN, Nagata WB, Loiola SHN, dos Santos BM, Soares FA, Laryssa Rosa SL, Baptista CB, Alves GB and Bresciani KDS (2020) Automated diagnosis of canine gastrointestinal parasites using image analysis. Pathogens (Basel, Switzerland) 9, 139.

Jimenez Castro PD, Howell SB, Schaefer JJ, Avramenko RW, Gilleard JS and Kaplan RM (2019) Multiple drug resistance in the canine hookworm Ancylostoma caninum: an emerging threat? Parasites \& Vectors 12, 576.

Kaplan RM (2020) Biology, epidemiology, diagnosis and management of anthelmintic resistance in gastrointestinal nematodes of livestock. Veterinary Clinics of North America: Food Animal Practice 36, 17-30.

Kitchen S, Ratnappan R, Han S, Leasure C, Grill E, Iqbal Z, Granger O, O'Halloran DM and Hawdon JM (2019) Isolation and characterization of a naturally occurring multidrug-resistant strain of the canine hookworm, Ancylostoma caninum. International Journal for Parasitology 49, 397-406.

Levecke B, Behnke JM, Ajjampur SS, Albonico M, Ame SM, Charlier J, Geiger SM, Hoa NT, Kamwa Ngassam RI, Kotze AC, McCarthy JS, Montresor A, Periago MV, Roy S, Tchuem Tchuenté LA, Thach DT and Vercruysse $\mathbf{J}$ (2011) A comparison of the sensitivity and fecal egg counts of the McMaster egg counting and Kato-Katz thick smear methods. PLoS Neglected Tropical Diseases 5, e1201.

Levecke B, Dobson RJ, Speybroeck N, Vercruysse J and Charlier J (2012) Novel insights in the faecal egg count reduction test for monitoring drug efficacy against gastrointestinal nematodes of veterinary importance. Veterinary Parasitology 188, 391-396.

Li Y, Zheng R, Wu Y, Chu K, Xu Q, Sun M and Smith ZJ (2019) A low-cost, automated parasite diagnostic system Via A portable, robotic microscope and deep learning. Journal of Biophotonics 12, e201800410.

Liu W, Anguelov D, Erhan D, Szegedy C, Reed S, Fu CY and Berg AC (2016) SSD: Single Shot Multibox Detector. In Liebe B, Matas J, Sebe N and Welling M (eds), Computer Vision - ECCV 2016. ECCV 2016. Lecture Notes in Computer Science, Vol. 9905. Cham: Springer.

Lu Q, Liu G, Xiao C, Hu C, Zhang S, Xu RX, Chu K, Xu Q and Smith ZJ (2018) A modular, open-source, slide-scanning microscope for diagnostic applications in resource-constrained settings. PLOS ONE 13, e0194063. doi: 10.1371/journal.pone.0194063.

MAFF (1986) Manual of Veterinary Parasitological Techniques, 3rd Edn. London: Her Majesty's Stationary Office. p. 160

McBride GB (2005) A proposal for strength-of-agreement criteria for Lin's concordance correlation coefficient. Hamilton: National Institute of Water and Atmospheric Research Client Report: HAM2005-062.

Mirams G (2016) FECPAKG2 Is a novel online faecal egg counting system for either remote location or laboratory/clinic based parasite FEC diagnostics. Proceedings of the Society of Sheep and Beef Cattle Veterinarians of the New Zealand Veterinary Association, 65-69.

Moser W, Bärenbold O, Mirams GJ, Cools P, Vlaminck J, Ali SM, Ame SM, Hattendorf J, Vounatsou P, Levecke B and Keiser J (2018) Diagnostic comparison between FECPAKG2 and the Kato-Katz method for analyzing soil-transmitted helminth eggs in stool. PLoS Neglected Tropical Diseases 12, e0006562. doi: 10.1371/journal.pntd.0006562.

Nagamori Y, Hall Sedlak R, DeRosa A, Pullins A, Cree T, Loenser M, Larson BS, Richard Boyd Smith RB and Richard Goldstein R (2020) Evaluation of the VETSCAN IMAGYST: an in-clinic canine and feline fecal parasite detection system integrated with a deep learning algorithm. Parasites \& Vectors 13, 346.

Nikolay B, Brooker SJ and Pullan RL (2014) Sensitivity of diagnostic tests for human soil-transmitted helminth infections: a meta-analysis in the absence of a true gold standard. International Journal for Parasitology 44, 765-774.

Paras KL, George MM, Vidyashankar AN and Kaplan RM (2018) Comparison of fecal egg counting methods in four livestock species. Veterinary Parasitology 257, 21-27.

Rashid MH, Stevenson MA, Waenga S, Mirams G, Campbell AJD, Vaughan JL and Jabbar A (2018) Comparison of McMaster and FECPAKG2 methods for counting nematode eggs in the faeces of alpacas. Parasites \& Vectors 2, 278.

Rinaldi L, Amadesi A, Dufourd E, Bosco A, Gadanho M, Lehebel A, Paola Maurelli M, Chauvin A, Charlier J, Cringoli G, Ravinet N and Chartier C (2019) Rapid assessment of faecal egg count and faecal egg count reduction through composite sampling in cattle. Parasites \& Vectors 12, 353.

Saeed MA and Jabbar A (2018) 'Smart diagnosis' of parasitic diseases by use of smartphones. Journal of Clinical Microbiology 56, e01469-17.

Scare JA, Slusarewicz P, Noel ML, Wielgus KM and Nielsen MK (2017) Evaluation of accuracy and precision of a smartphone based automated parasite egg counting system in comparison to the McMaster and MiniFLOTAC methods. Veterinary Parasitology 247, 85-92.

Scheild P, Lam DM, Thömmes A and Zöller L (2007) Telemicrobiology: a novel Tele-Medicine capability for mission support in the field of infectious medicine. Telemedicine Journal and e-Health 13, 108-117.

Shot MultiBox Detector. ECCV. Lecture Notes in Computer Science, vol. 9905. Cham: Springer.

Slusarewicz P, Pagano S, Mills C, Popa G, Chow KM, Mendenhall M, Rodgers DW and Nielsen MK (2016) Automated parasite faecal egg counting using fluorescence labelling, smartphone image capture and computational image analysis. International Journal for Parasitology 46, 485-493.

Sukas S, Van Dorst B, Kryj A, Lagatie O, De Malsche W and Stuyver LJ (2019) Development of a lab-on-a-disk platform with digital imaging for identification and counting of parasite eggs in human and animal stool. Micromachines 10, 852 .

Vercruysse J, Charlier J, Van Dijk J, Morgan ER, Geary T, von Samson-Himmelstjerna G and Claerebout E (2018) Control of helminth ruminant infections by 2030. Parasitology 145, 1655-1664.

Vlaminck J, Cools P, Albonico M, Ame S, Ayana M, Bethony J, Cringoli G, Dana D, Keiser J, Maurelli MP, Montresor A, Mekonnen Z, Mirams G, Corrêa-Oliveira R, Prichard R, Rashwan N, Rinaldi L, Sayasone S, Thomas E, Verweij JJ, Vercruysse J and Levecke B (2018) Comprehensive evaluation of stool-based diagnostic methods and benzimidazole resistance markers to assess drug efficacy and detect the emergence of anthelmintic resistance: a Starworms study protocol. PLoS Neglected Tropical Diseases 12, e0006912.

Vlaminck J, Cools P, Albonico M, Ame S, Ayana M, Cringoli G, Dana D, Keiser J, Maurelli MP, Matoso LF, Montresor A, Mekonnen Z, Mirams G, Corrêa-Oliveira R, Pinto SA, Rinaldi L, Sayasone S, Thomas E, Vercruysse J, Verweij JJ and Levecke B (2019) Therapeutic efficacy of albendazole against soil-transmitted helminthiasis in children measured by five diagnostic methods. PLoS Neglected Tropical Diseases 13, e0007471.

WHO (World Health Organization) (2019) Bench Aids for the Diagnosis of Intestinal Parasites, 2nd Edn. Geneva, Switzerland: WHO.

Zaffarano GP, Morandi B, Menegotto A, Ostanello F and Poglayen G (2018) Parasitological experiences in wild ruminants of South African preserves. Journal of Veterinary Medicine and Animal Health 10, 67-71. 